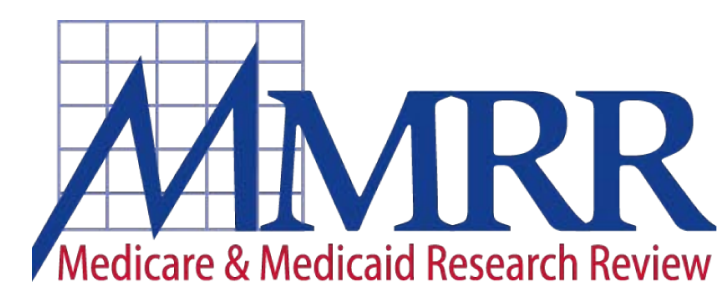

2013: Volume 3, Number 3

A publication of the Centers for Medicare \& Medicaid Services, Office of Information Products \& Data Analytics

\title{
Utilization of Dental Services Among Medicaid-Enrolled Children
}

\author{
Ellen Bouchery \\ Mathematica Policy Research
}

Objective: To assess what characteristics of children and their communities are associated with lower dental service use rates, to support development of strategies to target subgroups of children with lower utilization.

Data source: The Medicaid Analytic Extract (MAX) 5-percent sample file, known as MiniMAX 2008.

Methods: Multivariate logistic regression was used to assess the association between enrollee and county characteristics and dental preventive and treatment service utilization.

Principal Findings: There is substantial variation in service use by age. Relative to a 9-year-old, a 2 -year-old is 28 percentage points less likely, and a 15 -year-old is 15 percentage points less likely, to receive a preventive dental service. Children enrolled in Medicaid for only part of the year were significantly less likely to receive a preventive or a treatment service relative to children covered by Medicaid for the full year. For preventive care, children enrolled for nine months were 15 percentage points less likely to have a service. Those enrolled for six months were 30 points less likely; those enrolled for three months were 41 points less likely. Children eligible for Medicaid based on disability were 9 and 6 percentage points less likely to receive a preventive or treatment service, respectively, than their counterparts who were eligible based on income alone.

Conclusions: This study identifies some subgroups of children who are particularly underserved and for whom states may need to devote more attention.

Keywords: Dentistry, Dental Care, Medicaid, Pediatrics ISSN: 2159-0354

doi: http://dx.doi.org/10.5600/mmrr.003.03.b04 


\section{Medicare \& Medicaid Research Review} 2013: Volume 3, Number 3

\section{Mission Statement}

Medicare \& Medicaid Research Review is a peerreviewed, online journal reporting data and research that informs current and future directions of the Medicare, Medicaid, and Children's Health Insurance programs. The journal seeks to examine and evaluate health care coverage, quality and access to care for beneficiaries, and payment for health services.

\section{http://www.cms.gov/MMRR/}

\section{U.S. Department of Health \& Human Services Kathleen Sebelius Secretary}

\section{Centers for Medicare \& Medicaid Services Marilyn Tavenner Administrator}

Editor-in-Chief

David M. Bott, Ph.D.

The complete list of Editorial Staff and Editorial Board members may be found on the MMRR Web site (click link): $\underline{\text { MMRR Editorial Staff Page }}$

Contact: $\underline{\text { mmrr-editors@cms.hhs.gov }}$

Published by the Centers for Medicare \& Medicaid Services.

All material in the Medicare \& Medicaid Research

Review is in the public domain and may be duplicated without permission. Citation to source is requested.

\section{Introduction}

Untreated tooth decay in children can result in infection and pain that can affect such routine daily activities as eating, playing, and speaking. Moreover, the pain from dental decay can cause lack of attention during school and missed school days (CDC, 2013; Satcher, 2003; AAP, 2008a). Because of these impacts, the Centers for Disease Control and Prevention (CDC) included, as part of its Healthy People 2020 goals, specific improvements in oral health for children and adolescents: to reduce the proportion of dental caries in primary and permanent teeth, to reduce the proportion of children with untreated tooth decay, and to increase the proportion who receive oral health care (CDC, 2012). To support these goals, the Centers for Medicare \& Medicaid Services (CMS) developed-in consultation with states and stakeholders-an Oral Health Strategy (CMS, 2011a) for Medicaid and the Children's Health Insurance Program (CHIP), with the goals of increasing the proportion of children who receive any preventive dental service and increasing the rate of sealant use among children ages 6 to 9. CMS is working with states to develop strategies to achieve these goals.

Under Medicaid's Early and Periodic Screening, Diagnostic, and Treatment (EPSDT) benefit, most children enrolled in Medicaid are entitled to dental services, including, at a minimum, maintenance of dental health, relief of pain and infections, and restoration of teeth (CMS, 2012). According to the Secretary of the Department of Health and Human Services' 2012 Annual Report on the Quality of Care for Children in Medicaid and CHIP (DHHS, 2012), in fiscal year (FY) 2010, 41 percent of Medicaidenrolled children had received preventive dental care, such as a dental cleaning or application 
of fluoride or sealants, and 23 percent had received a dental-treatment service, such as a filling for a cavity. There are many reasons why Medicaid-enrolled children may not use dental services. One important factor may be limited access to or availability of dental services (CDC, 2012; CMS, 2011a). According to the Kaiser Commission on Medicaid and the Uninsured (2012), 15 percent of the U.S. population lives in areas where dental-provider shortages exist. Other barriers are lack of knowledge about the benefits of dental care, fear of dental procedures, low reimbursement rates, administrative burden for providers, transportation issues, and cultural and language-competency gaps (CDC, 2012; CMS, 2011a).

To support efforts to develop strategies to improve service use, this study analyzes data on use of dental services for Medicaid-enrolled children in nine states (Alabama, Alaska, Arkansas, Illinois, Iowa, Louisiana, Mississippi, New Hampshire, and Oklahoma) to assess what characteristics of children and their communities are associated with lower service use. Establishing this can help develop strategies to target subgroups of children with lower utilization rates.

\section{Methods}

This study uses Mini-MAX 2008, a 5-percent sample of the Medicaid Analytic eXtract (MAX) files for that year. MAX files are Medicaid administrative files, including person-level enrollment and claims data from all 50 states and the District of Columbia. Multivariate logistic regression analysis is used to identify factors associated with the observed dental-service utilization rates controlling for other factors. Because the Mini-MAX sample is stratified by state and basis of eligibility, this study's descriptive and multivariate analyses were weighted; SAS STAT software was used to adjust the standard errors to reflect the sample design.

We excluded from our analysis states that enrolled more than 10 percent of full-benefit children in comprehensive managed care plans or with a dental managed care plan (33 states). These states are excluded, because MAX data have not historically included comprehensive utilization data for managed care enrollees. Although reporting of dental services may be complete in some states (Byrd et al., 2012), evaluating the quality of the encounter data was beyond the scope of this study. These states may have feefor-service (FFS) claims for dental services for a subset of enrollees; however, the utilization of the FFS enrollees is generally not representative of the utilization of the full population in a state, because individuals enrolled in managed care programs generally are comparatively healthy. Nine additional states were excluded, because of incomplete reporting of procedure codes, leaving nine analysis states. Data are pooled across the analysis states.

Within these states, we excluded several types of enrollees: those who were enrolled in comprehensive managed care plans in Illinois and Iowa, those dually enrolled in Medicare, those with restricted Medicaid benefits, children under age 1 as of December 31, 2008, and those with fewer than three months of continuous enrollment in $2008 .{ }^{1}$

We measure use of: (1) dental preventive services by codes D1000-D1999 and (2) treatment services by codes D2000-D9999. Our analytic measure for each is an indicator of whether

\footnotetext{
${ }^{1}$ The Initial Core Set of Children's Health Care Quality Measures requires children to be 1 year old and continuously eligible for receipt of EPSDT services for at least 90 days (proxied by three months in MAX data) to be included in the dental service utilization measure (CMS, 2011b).
} 
Medicaid paid for at least one service of the given type in 2008 for each Medicaid enrollee. ${ }^{2}$

Explanatory variables were selected based on prior research suggesting a relationship between these factors and use of dental services. Previous studies have indicated that use of dental services is associated with age, gender, race, and ethnicity (CDC, 2012; Decker, 2011). We also look at two Medicaid characteristics: length of enrollment and eligibility as a result of disability. Length of enrollment is directly related to the likelihood of having a Medicaid-paid service. Disability is associated with increased risk of poor oral health (CDC, 2012; AAP, 2008a).

At the county level, we analyze urbanicity, because provider shortages are most pervasive in urban and rural areas (Kaiser Commission on Medicaid and the Uninsured, 2012), and transportation barriers are more likely to affect nonurban areas with limited public transportation. We combine counties into four groups based on the 2003 Urban Influence Codes developed by the U.S. Department of Agriculture's Economic Research Service (ERS). Median household income and insurance rates are analyzed, because lower-income communities, and those with higher proportions of uninsured residents, will generally have fewer private resources available to address care needs, but may be more likely to have publicly funded care options. The number of residents per dentist measures the availability of providers in a county, but it should be noted that we were unable to identify the proportion of these providers accepting Medicaid patients, which would have provided a more direct measure of the availability of providers to Medicaid enrollees.

\footnotetext{
${ }^{2}$ Institutional services are not included in this analysis. Also, services paid by Medicaid and provided by Indian Health Service, Federally Qualified Health Clinics, school-based clinics, and other public health providers are generally reported to MAX, but may be underreported in some states.
}

A recent study by Decker (2011) found a positive relationship between Medicaid payment rates for child prophylaxis in 2000 and 2008 and the likelihood that a child on Medicaid - as reported in the National Health Interview Survey (NHIS) - had seen a dentist in the last six months. While the Mini-MAX file includes data on Medicaid payment amounts for services provided, this information needs to be combined with a measure of the prevailing payment level for dental services in a locality to assess the competitiveness of the Medicaid payment rates relative to those for other payers. The Pew Center on the States has developed a measure of average Medicaid fees relative to median retail charges in the region for each state. ${ }^{3}$ We assess the relationship between this measure and dental service use rates in the next section. We do not include this measure in the multivariate model, because it is available only at the state level and there are numerous state-level policy and market factors that may affect use. Thus, we include a state of residence indicator variable in the model to broadly capture state-level factors.

The enrollee demographic and eligibility characteristics used in our analysis were derived from the Mini-MAX person summary (PS) file. Descriptive data on county population, number of active patient care dentists, median household income, percentage of population younger than 65 years old who are uninsured, and level of urbanicity in each enrollee's county of residence were obtained by linking the enrollee's Mini-MAX record to the 2009-2010 Area Resource File (DHHS, 2010) based on his or her last county of residence in 2008.

Exhibit 1 shows the number of observations and the distribution of children in the nine states

\footnotetext{
${ }^{3}$ The Pew Center on the States and the Medicaid-SCHIP Dental Association (MSDA) surveyed state Medicaid fees for five common children's procedures: examination, fluoride application, sealants, a basic filling, and tooth extraction. The Medicaid fees were compared to ADA survey data of the median retail charges of dentists in each state's region (The Pew Center on the States, 2010).
} 
Exhibit 1. Distribution of Medicaid-Enrolled Children and Average Receipt of Dental Services by Enrollee and Locality Characteristics, 2008

\begin{tabular}{|c|c|c|c|c|}
\hline & $\begin{array}{l}\text { Number of } \\
\text { Medicaid-Enrolled } \\
\text { Children in Sample }\end{array}$ & $\begin{array}{c}\text { Percentage of } \\
\text { Medicaid-Enrolled } \\
\text { Children }\end{array}$ & $\begin{array}{l}\text { Percentage Using } \\
\text { Preventive Service } \\
\text { (D1000-D1999) }\end{array}$ & $\begin{array}{c}\text { Percentage Using } \\
\text { Treatment Service } \\
\text { (D2000-D9999) }\end{array}$ \\
\hline Overall & 153,721 & 100 & 34 & 19 \\
\hline \multicolumn{5}{|l|}{ Enrollee-Level } \\
\hline \multicolumn{5}{|l|}{ Characteristics } \\
\hline Gender & - & - & - & - \\
\hline Male & 81,586 & 51 & 33 & 19 \\
\hline Female & 72,135 & 49 & 35 & 20 \\
\hline \multicolumn{5}{|l|}{ Age (as of December 31, } \\
\hline \multicolumn{5}{|l|}{ 2008) } \\
\hline 1 to 2 years & 23,120 & 16 & 9 & 2 \\
\hline 3 to 5 years & 29,999 & 20 & 38 & 16 \\
\hline 6 to 9 years & 36,922 & 24 & 44 & 27 \\
\hline 10 to 12 years & 24,527 & 15 & 42 & 24 \\
\hline 13 to 17 years & 39,153 & 24 & 33 & 23 \\
\hline \multicolumn{5}{|l|}{ Race/Ethnicity } \\
\hline White, Non-Hispanic & 62,171 & 41 & 35 & 20 \\
\hline Black, Non-Hispanic & 49,779 & 34 & 33 & 18 \\
\hline Hispanic & 19,403 & 14 & 36 & 20 \\
\hline American Indian/Alaskan & 5,648 & 3 & 37 & 26 \\
\hline \multicolumn{5}{|l|}{ Native, Non-Hispanic } \\
\hline $\begin{array}{l}\text { Asian/Native Hawaiian/ } \\
\text { Other Pacific Islander }\end{array}$ & 2,415 & 1 & 32 & 19 \\
\hline More than one race & 528 & 0 & 31 & 17 \\
\hline Unknown & 13,777 & 7 & 30 & 15 \\
\hline \multicolumn{5}{|l|}{ Basis of Eligibility } \\
\hline Disabled $^{1}$ & 25,982 & 5 & 35 & 20 \\
\hline Nondisabled & 127,739 & 95 & 34 & 19 \\
\hline \multicolumn{5}{|l|}{ Length of Medicaid } \\
\hline \multicolumn{5}{|l|}{ Enrollment } \\
\hline 3 to 5 months & 10,043 & 7 & 13 & 7 \\
\hline 6 to 8 months & 11,351 & 8 & 21 & 12 \\
\hline 9 to 10 months & 15,599 & 11 & 33 & 19 \\
\hline 11 to 12 months & 116,728 & 75 & 37 & 21 \\
\hline \multicolumn{5}{|l|}{ County-Level Data } \\
\hline \multicolumn{5}{|l|}{ Urbanicity $^{2}$} \\
\hline Large metro area & 47,608 & 33 & 32 & 17 \\
\hline Small metro area & 36,290 & 22 & 36 & 20 \\
\hline $\begin{array}{l}\text { Noncore adjacent to metro } \\
\text { area or micropolitan area }\end{array}$ & 67,094 & 44 & 35 & 19 \\
\hline
\end{tabular}


Exhibit 1 Continued. Distribution of Medicaid-Enrolled Children and Average Receipt of Dental Services by Enrollee and Locality Characteristics, 2008

\begin{tabular}{|c|c|c|c|c|}
\hline & $\begin{array}{c}\text { Number of } \\
\text { Medicaid-Enrolled } \\
\text { Children in Sample }\end{array}$ & $\begin{array}{c}\text { Percentage of } \\
\text { Medicaid-Enrolled } \\
\text { Children }\end{array}$ & $\begin{array}{l}\text { Percentage Using } \\
\text { Preventive Service } \\
\text { (D1000-D1999) }\end{array}$ & $\begin{array}{l}\text { Percentage Using } \\
\text { Treatment Service } \\
\text { (D2000-D9999) }\end{array}$ \\
\hline Noncore nonadjacent area & 2,729 & 2 & 37 & 23 \\
\hline \multicolumn{5}{|l|}{ Median Household Income } \\
\hline$<\$ 35,000$ & 22,191 & 15 & 37 & 22 \\
\hline$\$ 35,000-\$ 49,999$ & 73,604 & 51 & 35 & 20 \\
\hline$\$ 50,000-\$ 64,999$ & 41,870 & 27 & 31 & 16 \\
\hline$\$ 65,000+$ & 16,056 & 8 & 31 & 18 \\
\hline \multicolumn{5}{|l|}{ Percent under 65 Without } \\
\hline \multicolumn{5}{|l|}{ Health Insurance } \\
\hline Less than $20 \%$ uninsured & 106,765 & 67 & 34 & 18 \\
\hline $20 \%$ or more uninsured & 46,956 & 33 & 34 & 20 \\
\hline \multicolumn{5}{|l|}{ Population per Dentist } \\
\hline $\begin{array}{l}\text { Less than } 2,000 \text { persons } \\
\text { per dentist }\end{array}$ & 47,798 & 30 & 33 & 18 \\
\hline $\begin{array}{l}2,000 \text { to } 2,999 \text { persons per } \\
\text { dentist }\end{array}$ & 52,945 & 34 & 33 & 18 \\
\hline $\begin{array}{l}3,000 \text { to } 3,999 \text { persons per } \\
\text { dentist }\end{array}$ & 26,204 & 18 & 35 & 20 \\
\hline $\begin{array}{l}4,000 \text { or more persons per } \\
\text { dentist }\end{array}$ & 26,774 & 18 & 36 & 21 \\
\hline \multicolumn{5}{|c|}{$\begin{array}{l}\text { NOTES: Includes only full-benefit, non-managed care enrolled children ages } 1 \text { to } 17 \text { with at least three consecutive months of Medicaid } \\
\text { enrollment in 2008. Estimates were weighted using the Mini-MAX sample weights. }\end{array}$} \\
\hline \multicolumn{5}{|c|}{$\begin{array}{l}{ }^{2} \text { Large metropolitan areas contain core areas with at least a million residents. Small metropolitan areas have a core area with 50,000 to a million } \\
\text { residents. Micropolitan areas have a core containing at least 10,000, but less than 50,000 residents. These areas include counties adjacent to the } \\
\text { core that have a high degree of social and economic integration. Non-core, non-adjacent areas contain less than 10,000 residents and are not } \\
\text { adjacent to an urban area. More detail can be found at http://www.ers.usda.gov/Data/UrbanInfluenceCodes/. } \\
\text { SOURCE: Mathematica analysis of the Mini-MAX 2008. }\end{array}$} \\
\hline
\end{tabular}

by the demographic, Medicaid enrollment, and county characteristics analyzed in this study.

\section{Findings}

In the nine FFS states, among children 1 to 17 years old with at least three months of continuous enrollment in Medicaid, 34 percent had a preventive service, and 19 percent had a treatment service, paid by Medicaid in 2008. Utilization of preventive services ranged from 51 percent in New
Hampshire to 25 percent in Illinois (Exhibit 2). ${ }^{4}$ Five of the 9 states had a dental-treatment use rate between 23 and 26 percent. Illinois had the lowest use rate of dental-treatment services-13 percent.

In the last two columns of Exhibit 1, we display the proportion of Medicaid-enrolled children using dental prevention and treatment services by demographic and county characteristics. There is

\footnotetext{
${ }^{4}$ Substantial discrepancies between these estimates and those from the CMS-416 reports for FY 2009 were identified in some states. The source and reason for these differences is unknown.
} 
Exhibit 2. Dental Use Among Medicaid-Enrolled Children 1 to 17 Years, 2008

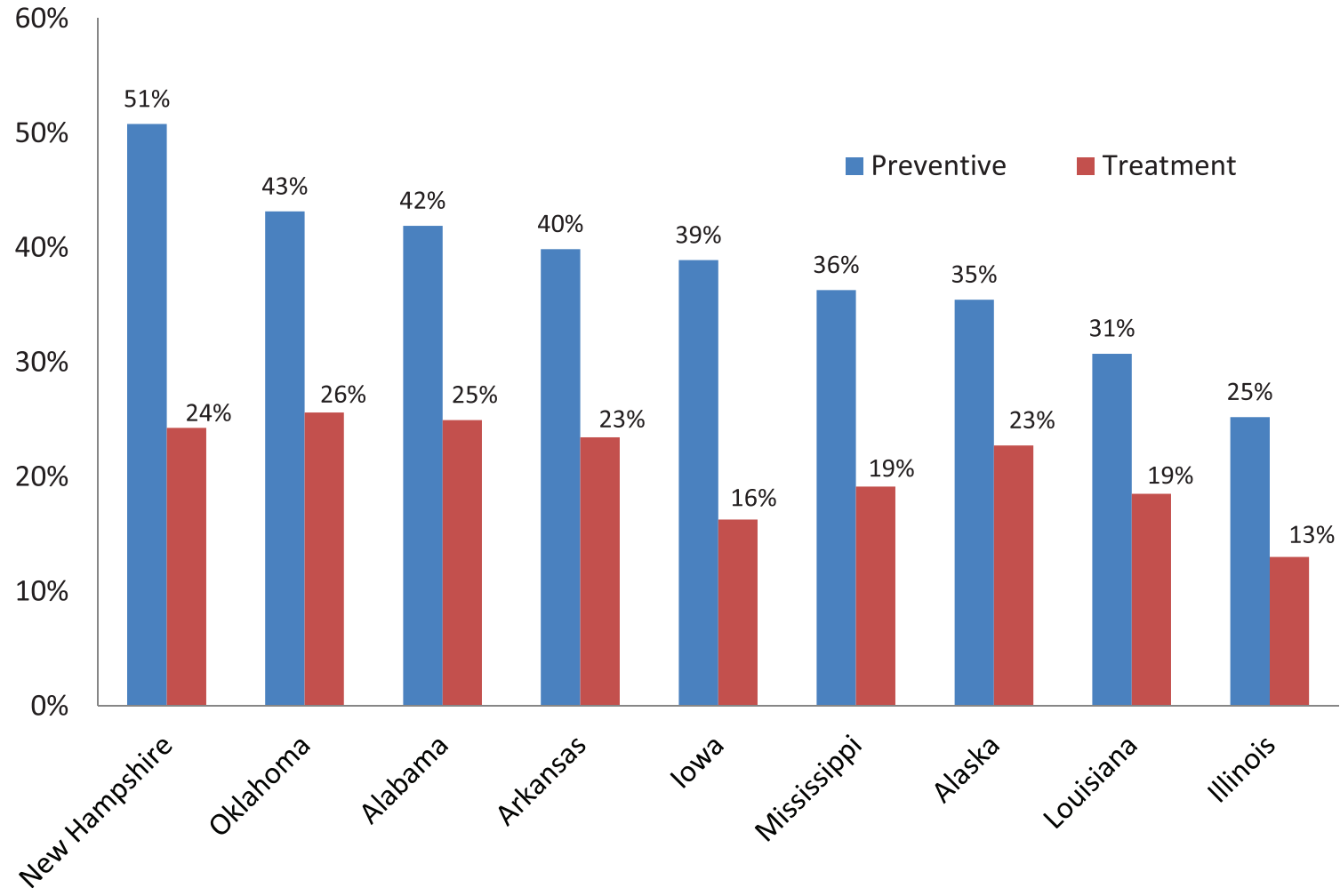

SOURCE: Mathematica analysis of Mini-MAX, 2008. $n=153,721$.

substantial variation by age. The American Academy of Pediatrics (AAP) recommends that children have their first dental visit at 1-year-old (AAP, 2008b), but only 9 percent of children 1 to 2 years old used a preventive service. Thus, it may be that many parents are unaware of this recommendation, or that dentists generally do not see patients in this age group. Children 3 to 5 years old have substantially higher preventive-service utilization (38 percent). The rate of preventive-service utilization peaks among children 6 to 9 years old (44 percent).

Children 10 to 12 had slightly lower preventiveservice use rates (42 percent). Adolescents 13 to 17 years old had somewhat lower use rates than some younger age groups (33 percent). There is also substantial variation in dental service use by length of Medicaid enrollment: 13 percent of children enrolled for 3 to 5 months received preventive dental care, in contrast to 37 percent of children enrolled for 11 to 12 months.
The CMS Oral Health Strategy aims to increase the percentage of Medicaid-enrolled children 6 to 9 years old with a sealant on a permanent molar. In Exhibit 3 we display the proportion of children in this age range receiving any preventive dental care and a sealant service. Similar to the average across all age groups, among children 6 to 9, New Hampshire had the highest rate of preventive service receipt (63 percent) and Illinois had the lowest (35 percent). Seven of the states had a sealant use rate of 10 to 14 percent. Alaska and New Hampshire had the highest sealant rates at 20 and 23 percent, respectively. It is notable that in a Pew (2010) study of Medicaid program policies related to dental care, Alaska and New Hampshire were the only states among those in this study that had sealant programs in place at between 75 and 100 percent of high-risk schools.2 These two states also did not require children to have a dentist's exam before a hygienist could see a child in a school sealant clinic. 
Exhibit 3. Dental Service Use Among Medicaid-Enrolled Children 6 to 9 Years, 2008

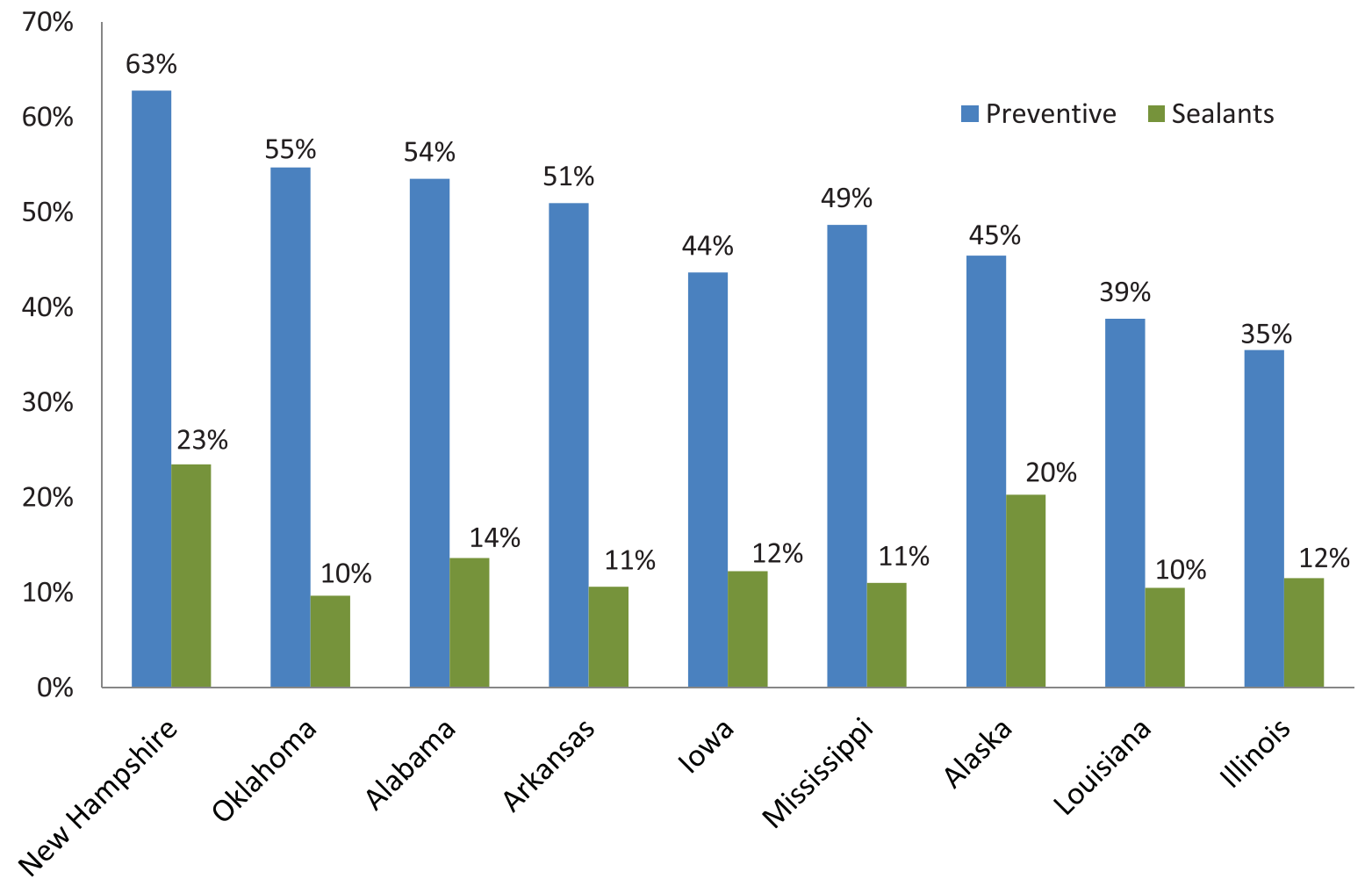

SOURCE: Mathematica analysis of Mini-MAX, 2008. $\mathrm{n}=36,922$.

Exhibits 4 and 5 compare the average Medicaid fee as a proportion of the median retail charge with preventive and treatment service use rates, respectively. New Hampshire, which has the fourthhighest fee proportion, has the highest preventive and third-highest treatment service utilization rate. Alaska has the highest fee proportion, but the third-lowest preventive-care and fourth-highest treatment utilization rate. Illinois, which has the lowest utilization for preventive and treatment services, has the second-lowest fee proportion. Iowa, which has the lowest fee proportion, has the median preventive-care utilization rate and second-lowest treatment service utilization rate. Thus, while the trend lines indicate there is a positive relationship between the fee proportion and use, it appears there are other significant factors associated with use. Since this study is limited to nine states, we tested the sensitivity of the positive relationship between the fee proportion and use to exclusion of each of the states included in this analysis. The positive relationship for treatment services is robust to exclusion of each of the analysis states; however, the positive relationship for preventive services is sensitive to inclusion of Illinois, which has the second-lowest fee proportion and lowest utilization rate.

The logistic regression results are generally consistent with the descriptive findings. In Exhibit 6 , we present the estimated marginal effect for each factor. When we examine the personal characteristics of the Medicaid enrollee, the multivariate results indicate substantial variation in service use by age, just as the descriptive results did. The results indicate that a 2 -year-old is 28 percentage points less likely to receive a dental service than a 9-year-old. And a 15 -year-old is 15 percentage points less likely than a 9-year-old to use a preventive service. Regression results indicate preventive and treatment service use peak at 10 and 11 years old, respectively, and then begins to decline. 
Exhibit 4. Relationship Between Average Medicaid Fee as a Percentage of the Median Retail Charge and Preventive Service Use, 2008

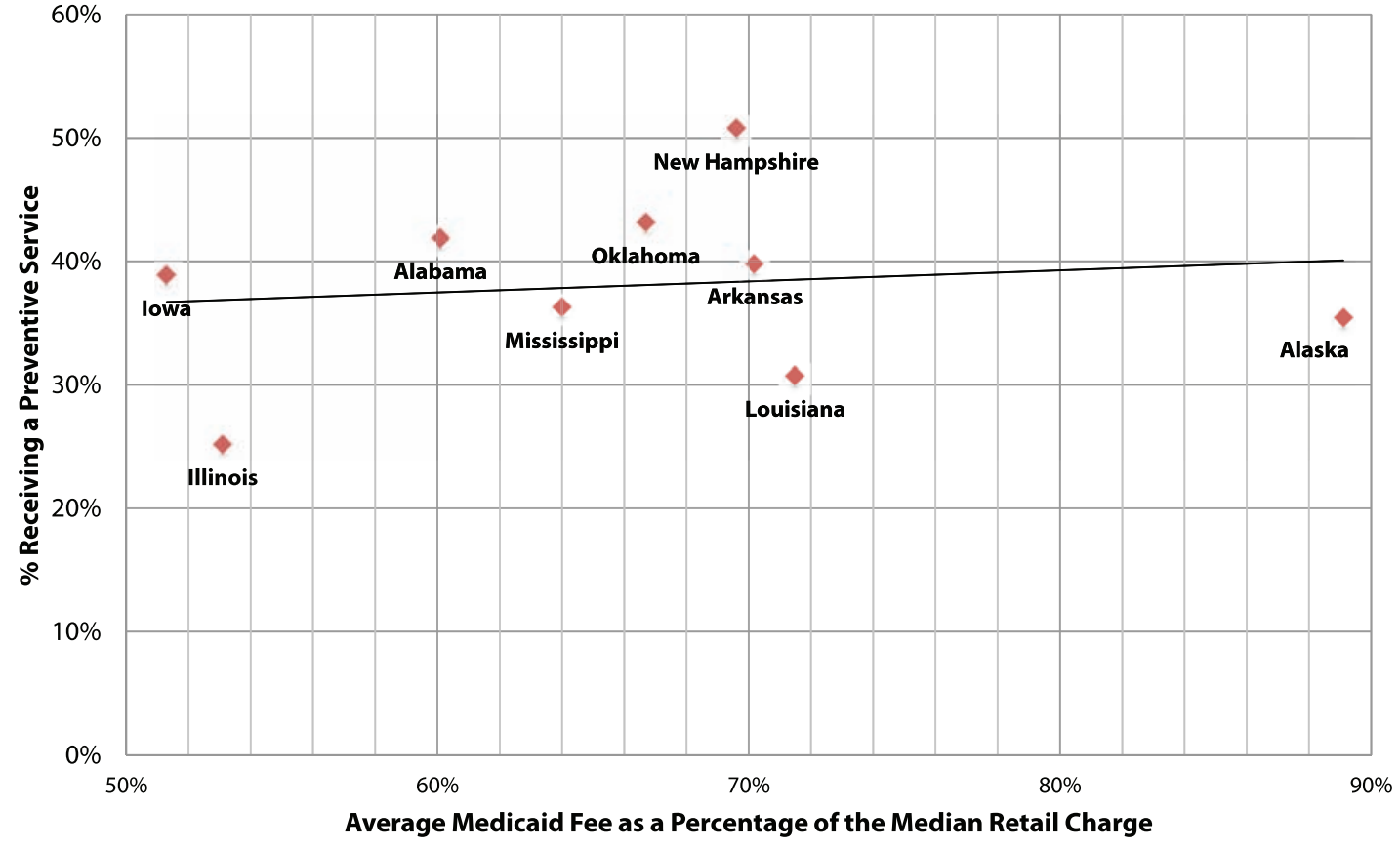

SOURCE: Average Medicaid fee relative to median retail charge obtained from The Pew Center on the States (2010, February; p. 69). Percentage receiving preventive service from Mathematica analysis of Mini-MAX, 2008, n = 153,721.

Exhibit 5. Relationship Between Average Medicaid Fee as a Percentage of the Median Retail Charge and Treatment Service Use, 2008

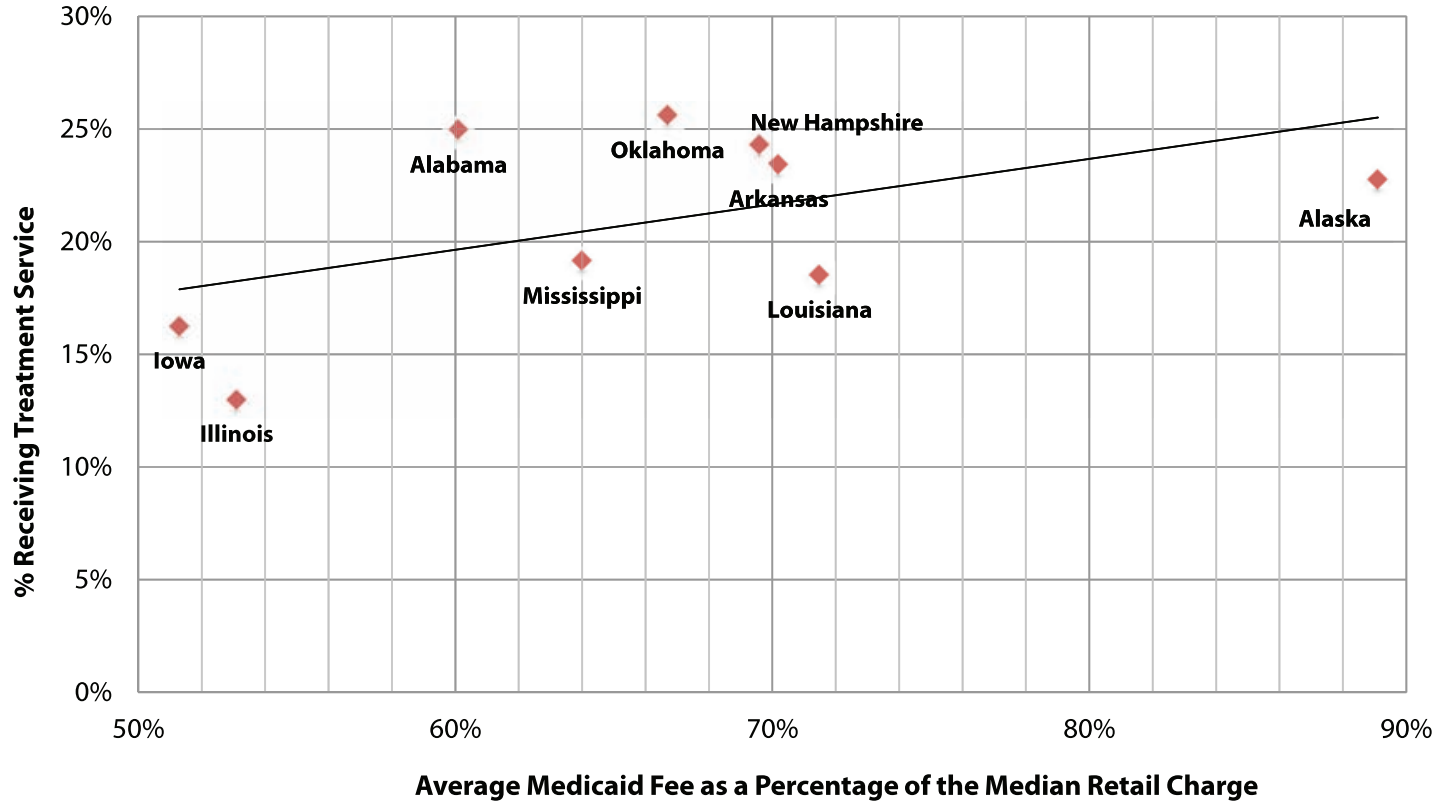

SOURCE: Average Medicaid fee relative to median retail charge obtained from The Pew Center on the States (2010, February; p. 69). Percentage receiving preventive service from Mathematica analysis of Mini-MAX, 2008, n = 153,721. 
Exhibit 6. Estimated Percentage-Point Change in the Probability That a Medicaid-Enrolled Child Has Had a Dental Service

\begin{tabular}{|c|c|c|c|c|}
\hline \multirow[b]{3}{*}{ Characteristic } & \multicolumn{2}{|c|}{ Received a Preventive Service } & \multicolumn{2}{|c|}{ Received a Treatment Service } \\
\hline & Percentage Point & & Percentage Poir & \\
\hline & Difference & P-value & Difference & P-value \\
\hline \multicolumn{5}{|l|}{ Enrollee-Level } \\
\hline \multicolumn{5}{|l|}{ Gender Versus Male } \\
\hline Female & 1.7 & $<.0001$ & 1.5 & $<.0001$ \\
\hline \multicolumn{5}{|l|}{ Age Versus 9 Years Old } \\
\hline 3 years old & -27.6 & $<.0001$ & -19.4 & $<.0001$ \\
\hline 6 years old & -8.6 & $<.0001$ & -8.9 & $<.0001$ \\
\hline 12 years old & -2.2 & $<.0001$ & 1.8 & $<.0001$ \\
\hline 15 years old & -15.4 & $<.0001$ & -4.3 & $<.0001$ \\
\hline \multicolumn{5}{|l|}{ Race/Ethnicity Versus } \\
\hline \multicolumn{5}{|l|}{ White, Non-Hispanic } \\
\hline Black, Non-Hispanic & -1.8 & $<.0001$ & -3.9 & $<.0001$ \\
\hline Hispanic & 7.8 & $<.0001$ & 7.3 & $<.0001$ \\
\hline $\begin{array}{l}\text { American Indian/Alaskan } \\
\text { Native, Non-Hispanic }\end{array}$ & -5.0 & $<.0001$ & 1.4 & 0.13 \\
\hline $\begin{array}{l}\text { Asian/Native Hawaiian/ } \\
\text { Other Pacific Islander }\end{array}$ & 1.0 & 0.44 & 2.3 & 0.08 \\
\hline More than one race & -2.7 & 0.29 & 0.5 & 0.85 \\
\hline \multicolumn{5}{|l|}{ Enrollee-Level } \\
\hline Unknown & 0.5 & 0.44 & -0.3 & 0.61 \\
\hline \multicolumn{5}{|l|}{ Disabled Versus } \\
\hline \multicolumn{5}{|l|}{ Nondisabled 1} \\
\hline Disabled & -8.5 & $<.0001$ & -6.1 & $<.0001$ \\
\hline \multicolumn{5}{|l|}{ Length of Medicaid } \\
\hline \multicolumn{5}{|l|}{ Enrollment Versus 12} \\
\hline \multicolumn{5}{|l|}{ Months Enrolled } \\
\hline 3 months enrolled & -41.3 & $<.0001$ & -20.8 & $<.0001$ \\
\hline 6 months enrolled & -29.9 & $<.0001$ & -16.2 & $<.0001$ \\
\hline 9 months enrolled & -15.4 & $<.0001$ & -9.4 & $<.0001$ \\
\hline \multicolumn{5}{|l|}{ County or State-Level } \\
\hline \multicolumn{5}{|l|}{ Urbanicity Versus Small } \\
\hline \multicolumn{5}{|l|}{ Metro Area } \\
\hline Large metro area & 5.9 & $<.0001$ & 2.9 & $<.0001$ \\
\hline $\begin{array}{l}\text { Noncore adjacent to metro } \\
\text { area or micropolitan area }\end{array}$ & -0.4 & 0.35 & -1.2 & 0.01 \\
\hline Noncore nonadjacent area & -1.5 & 0.23 & 1.3 & 0.28 \\
\hline \multicolumn{5}{|l|}{ Median Household Income } \\
\hline \multicolumn{5}{|l|}{ Versus $\$ 50,000-\$ 64,999$} \\
\hline$<\$ 35,000$ & 1.0 & 0.16 & 0.3 & 0.66 \\
\hline
\end{tabular}

(Continued) 
Exhibit 6 Continued. Estimated Percentage-Point Change in the Probability That a Medicaid-Enrolled Child Has Had a Dental Service

\begin{tabular}{lcccc}
\hline \multicolumn{1}{c}{\begin{tabular}{c} 
Received a Preventive Service \\
\multicolumn{1}{c}{ Charcentage Point } \\
Difference
\end{tabular}} & P-value & $\begin{array}{c}\text { Received a Treatment Service } \\
\text { Percentage Point } \\
\text { Difference }\end{array}$ & P-value \\
\hline $\begin{array}{l}\text { \$35,000-\$49,999 } \\
\$ 65,000+\end{array}$ & 0.0 & 0.96 & -0.5 & 0.32 \\
20 Percent or More Under 65 & -1.3 & 0.04 & 2.1 & $<0.01$ \\
Without Health Insurance & -1.5 & $<0.01$ & -0.3 & 0.50 \\
Versus Less Than 20\% & & & & \\
Residents Per Dentist Versus & & & & \\
3,000 Residents Per Dentist & & & 0.1 & 0.34 \\
2,000 residents per dentist & 0.2 & 0.01 & -0.1 & 0.34 \\
4,000 residents per dentist & -0.2 & 0.01 & & $<.0001$ \\
State Versus Iowa & & & 14.7 & $<.0001$ \\
Alabama & 2.9 & $<0.01$ & 7.9 & $<.0001$ \\
Alaska & 0.9 & 0.40 & 10.5 & $<.0001$ \\
Arkansas & 0.5 & 0.54 & -10.7 & 0.04 \\
Illinois & -27.3 & $<.0001$ & 2.0 & $<.0001$ \\
Louisiana & -13.3 & $<.0001$ & 8.1 & $<.0001$ \\
Mississippi & -0.7 & 0.41 & 7.8 & $<.0001$ \\
New Hampshire & 9.9 & $<.0001$ & 12.4 & \\
Oklahoma & 3.4 & $<.0001$ & & \\
\hline
\end{tabular}

NOTES: Analysis includes only full-benefit, non-managed care enrolled children ages 1 to 17 with at least three consecutive months of Medicaid enrollment in 2008. Estimates were weighted using the Mini-MAX sample weights. The estimates assume the following enrollee characteristics, varying only the characteristic being analyzed in each row: a 9-year-old, White, Non-Hispanic, nondisabled, male, enrolled in Medicaid for 12 months in 2008 , living in a small, metropolitan area in Iowa, earning median household income of $\$ 50,000-\$ 64,000$, with 3,000 residents per dentist, and less than 20 percent of the nonelderly population uninsured.

${ }^{1}$ Children identified as eligible for Medicaid on the basis of disability in their last month of Medicaid enrollment in 2008 were assigned to the disabled eligibility group.

${ }^{2}$ Large metropolitan areas contain core areas with at least a million residents. Small metropolitan areas have a core area with 50,000 to a million residents. Micropolitan areas have a core containing at least 10,000, but less than 50,000 residents. These areas include counties adjacent to the core that have a high degree of social and economic integration. Non-core, non-adjacent areas contain less than 10,000 residents are not adjacent to an urban area. More detail can be found at http://www.ers.usda.gov/Data/UrbanInfluenceCodes/.

SOURCE: Mathematica analysis of the Mini-MAX 2008.

Not surprisingly, children enrolled in Medicaid for only part of the year were significantly less likely to receive a preventive or treatment service when compared to children who were covered by Medicaid for the full year. For preventive care, children enrolled for nine months were 15 percentage points less likely to have a service. Those enrolled for six months were 30 points less likely; those enrolled for three months were 41 points less likely. Children eligible for
Medicaid based on disability were 9 and 6 percentage points less likely to receive a preventive or treatment service, respectively, than their counterparts who were eligible based on income alone.

Turning to the characteristics of the enrollee's county, most of the differences estimated were small with the exception of the estimated differencein use for enrollees in large metropolitan areas. These enrollees were 6 and 3 percentage points more likely to receive 
a preventive or treatment service, respectively, than enrollees in small metropolitan areas. Surprisingly, the number of residents per dentist in a county had little association with use rates. This measure of the number of dentists available in an area may not be a good proxy for the number of dentists accepting Medicaid patients in a county.

\section{Discussion}

The findings of this study are limited in several ways. First, this study addresses dental care in only nine states; therefore, it is not representative of Medicaid dental care overall. Improved reporting and more detailed analysis of the encounter data on dental services included in MAX may allow for encounter data from states with managed care coverage to be included in a future study. A second significant limitation of this study was lack of information on the variation in state-specific policies for coverage, reimbursement, and administration of Medicaid dental services. Controlling for these differences would significantly improve the analysis. Finally, the measure of provider availability would be improved by focusing directly on the number of providers accepting Medicaid patients. Thus, this analysis would be improved by adding data for additional states, and by controlling for additional factors associated with Medicaid administrative policies and the market for dental services.

Despitetheselimitations, this studyhasidentified subgroups of children with lower utilization rates, which may be targeted as part of CDC and CMS efforts to improve oral health care.

Substantial differences in use by age suggest that adolescents as well as very young children might be appropriate targets for outreach. Clinical experts have noted the importance of early dental care. The American Academy of Pediatric Dentistry (AAPD), the American Dental Association, and the American Association of Public Health Dentistry recommend that the initial oral exam occur no later than 12 months of age (AAP, 2008b), and the AAP (2008b) notes that successful prevention of dental diseases requires dental care in the first year of life. Because young children more frequently see a primary care provider than a dentist, one way to reach young children is to allow Medicaid reimbursement for dental services provided by primary care medical providers (The Pew Charitable Trusts, 2011). Adolescents also have significant need for care, because they have higher rates of dental caries relative to their younger counterparts (AAPD, 2010). Adolescence is also a time that can bring changes that may impact oral health, including eruption of remaining permanent teeth.

Consistent Medicaid enrollment is also an important factor associated with Medicaid service use; however, we do not measure receipt of services through other payment sources. Nevertheless, improving the constancy of Medicaid enrollment may encourage treatment use. Alternatively, outreach efforts with families at the time they enroll in Medicaid, to more readily connect them to a dental provider and make them aware of dental benefits, may encourage increased service use in the initial months of Medicaid enrollment.

Children qualifying for Medicaid due to disability were substantially less likely to receive dental treatment than their counterparts who qualified based on family income alone. The particular needs of patients with disabilities will vary with their disability, and providers may require special training or equipment to meet these needs. Dental care may receive less attention, because of the demands of meeting the other health needs of these patients. In addition, individuals with disabilities may have barriers to communicating dental-care needs to caregivers, resulting in delayed treatment. Analysis of the needs of this population, and barriers to their access, is recommended to address this gap. 


\section{Correspondence}

Ellen Bouchery, M.S., Mathematica Policy Research, 1100 1st Street, NE Washington, DC 20002-4221, ebouchery@mathematica-mpr.com, Tel. 202-484-4697

\section{Acknowledgment}

I would like to acknowledge the contribution of Rosalie Malsberger to this research. Ms. Malsberger provided programming and analytic support for this research.

\section{References}

American Academy of Pediatrics (2008a). Promoting Oral Health. Bright Futures: Guidelines for Health Supervision of Infants, Children, and Adolescents, 3rd Edition, Theme 7. Retrieved from http:// brightfutures.aap.org/pdfs/guidelines_pdf/8promoting_oral_health.pdf

American Academy of Pediatrics. (2008b, December). Preventive Oral Health Intervention for Pediatricians: Section on Pediatric Dentistry and Oral Health. Pediatrics, 122(6), 1387-1394. Retrieved from http://pediatrics. aappublications.org/content/122/6/1387. full.html PubMed http://dx.doi.org/10.1542/ peds.2008-2577

American Academy of Pediatric Dentistry (2010). Guideline on Adolescent Oral Health Care. Retrieved from http://www.aapd.org/media/ Policies_Guidelines/G_Adoleshealth.pdf

Byrd, V. L. H., Dodd, A. H., Malsberger, R., \& Zlatinov, A. (2012, July). Assessing the Usability of MAX 2008 Encounter Data for Enrollees in Comprehensive Managed Care (MAX Medicaid Policy Brief No. 7), 1-13. Retrieved from http://www.cms.gov/Research-Statistics-Dataand-Systems/Computer-Data-and-Systems/ MedicaidDataSourcesGenInfo/Downloads/ MAX_IB7_EncounterData_071312.pdf
CDC (Centers for Disease Control and Prevention). (2013, July). Children's Oral Health. Retrieved from the Centers for Disease Control and Prevention, Division of Oral Health Web site: http://www.cdc.gov/OralHealth/children_ adults/child.htm

CDC (Centers for Disease Control and Prevention). (2012, October). Healthy People 2020, Oral Health: Objectives. Retrieved from the US Department of Health and Human Services Web site: http://www. healthypeople.gov/2020/topicsobjectives2020/ objectiveslist.aspx? topicId $=32$

CMS (Centers for Medicare \& Medicaid Services). (2012). Early and Periodic Screening, Diagnostic, and Treatment. Retrieved from the Centers for Medicare \& Medicaid Services Web site: http:// www.medicaid.gov/Medicaid-CHIP-ProgramInformation/By-Topics/Benefits/Early-PeriodicScreening-Diagnosis-and-Treatment.html

CMS (Centers for Medicare and Medicaid Services). (2011a, April). CMS Oral Health Strategy: Improving Access to and Utilization of Oral Health Services for Children in Medicaid and CHIP Programs. Retrieved from the Centers for Medicare \& Medicaid Services Web site: http:// www.medicaid.gov/Medicaid-CHIP-ProgramInformation/By-Topics/Quality-of-Care/ Downloads/CMS-Oral-Health-Strategy.pdf

CMS (Centers for Medicare and Medicaid Services). (2011b, December). Initial Core Set of Children's Health Care Quality Measures: Technical Specifications and Resource Manual for Federal Fiscal Year 2011 Reporting. Retrieved from: http://64.64.16.103/wp-content/uploads/2013/01/ initialcoresetresoucemanual.pdf

Decker, S. L. (2011, July 13). Medicaid Payment Levels to Dentists and Access to Dental Care 
Among Children and Adolescents. Journal of the American Medical Association, 306(2), 187-193. PubMed http://dx.doi.org/10.1001/ jama.2011.956

DHHS (US Department of Health and Human Services). (2010, August). User Documentation for the Area Resource File (ARF) 2009-2010 Release. Rockville, MD: Bureau of Health Professions.

DHHS (US Department of Health and Human Services).(2012, December).2012 Annual Report on the Quality of Care for Children in Medicaid and CHIP. Retrieved from http://www.medicaid. gov/Medicaid-CHIP-Program-Information/ByTopics/Quality-of-Care/Downloads/2012-AnnSec-Rept.pdf

Kaiser Commission on Medicaid and the Uninsured. (2012, June). Oral Health in the US: Key Facts. p. 2. Retrieved from the Henry J. Kaiser
Family Foundation Web site: http://www.kff.org/ uninsured/8324.cfm

The Pew Center on the States. (2010, February). The Cost of Delay: State Dental Policies Fail One in Five Children. Retrieved from the Pew Center on the States Web site: http://www.pewtrusts. org/uploadedFiles/Cost_of_Delay_web.pdf

The Pew Charitable Trusts. (2011, August). Reimbursing Physicians for Fluoride Varnish. Retrieved from the Pew Charitable Trusts, State and Consumer Initiatives Web site: http://www. pewstates.org/research/analysis/reimbursingphysicians-for-fluoride-varnish-85899377335

Satcher, D. (2003). Oral Health and Learning: When Children's Health Suffers So Does Their Ability to Learn. National Maternal and Child Oral Health Resource Center. Retrieved from http://www.mchoralhealth.org/PDFs/ learningfactsheet.pdf 